\title{
The push of social pain: Does rejection's sting motivate subsequent social reconnection?
}

\author{
David S. Chester ${ }^{1}$ C. Nathan DeWall ${ }^{1} \cdot$ Richard S. Pond Jr. ${ }^{2}$
}

Published online: 24 February 2016

(C) Psychonomic Society, Inc. 2016

\begin{abstract}
Physical pain motivates the healing of somatic injuries, yet it remains unknown whether social pain serves a similarly reparative function toward social injuries. Given the substantial overlap between physical and social pain, we predicted that social pain would mediate the effect of rejection on greater motivation for social reconnection and affiliative behavior toward rejecters. In Study 1, the effect of rejection on an increased need to belong was mediated by reports of more intense social pain. In Study 2, three neural signatures of social pain (i.e., activity in the dorsal anterior cingulate cortex, left and right anterior insula during social rejection), each predicted greater behavioral proximity to rejecters. Our findings reify the overlap between social and physical pain. Furthermore, these results are some of the first to demonstrate the reparative nature of social pain and lend insight into how this process may be harnessed to promote postrejection reconnection.
\end{abstract}

Keywords Social rejection · Social pain · Affiliation · Reconnection

Human beings possess an elemental need to belong (Baumeister \& Leary, 1995). Social rejection thwarts this need, harming both physical and mental health (Eisenberger, 2013). People actively seek to heal the damage of such social

David S. Chester

davidchester@uky.edu

1 Department of Psychology, University of Kentucky, 0003 Kastle Hall, Lexington, KY 40506, USA

2 Department of Psychology, University of North Carolina, Wilmington, USA injuries through affiliative behaviors that promote social reconnection (Maner, DeWall, Baumeister, \& Schaller, 2007; Romero-Canyas et al., 2010; Watson-Jones, Whitehouse, \& Legare, 2016). Yet the mechanism underlying postrejection reconnection remains unknown. Given pain's ability to motivate healing (Wall, 1999), we conducted two studies to test the prediction that the pain of rejection would motivate social reconnection (i.e., social healing) after an instance of social rejection (i.e., a social injury).

\section{The desire to reconnect: healing the social injury}

When individuals experience damage to a social bond, they often attempt to repair it through affiliative behavior (DeWall \& Richman, 2011; Williams, 2009). This basic logic underlies Maner and colleagues' (2007) social reconnection hypothesis, which states that social rejection motivates individuals to fulfill their need for social connection by promoting affiliative and prosocial behavior toward new interaction targets. This hypothesis was supported by evidence that rejected individuals, as compared to their accepted counterparts, showed increased motivation to meet new people, to work cooperatively rather than alone with them, to perceive them more positively, and to act prosocially toward them. Demonstrating the strength of this motivation for reinclusion, people will conform (DeWall, 2010; Williams, Cheung, \& Choi, 2000), smoke cigarettes (DeWall \& Pond, 2011), and spend money in the service of gaining social reconnection (Mead, Baumeister, Stillman, Rawn, \& Vohs, 2011). This motivation to reconnect manifests very early in the stream of human cognitive processes, with rejected individuals showing attentional and behavioral biases toward signs of acceptance (e.g., smiling faces; DeWall, Maner, \& Rouby, 2009). Indeed, individuals' affiliative tendencies after rejection are not limited to 
new individuals but can extend to the rejecters themselves (Balliet \& Ferris, 2013; Romero-Canyas et al., 2010; Williams \& Sommer, 1997). Even young children seek to reconnect with in-group members who exclude them (Watson-Jones et al., 2016).

These findings may appear to stand in stark opposition to the robust corpus of research that demonstrates the increased antisocial and decreased prosocial tendencies of rejected individuals (e.g., Twenge, Baumeister, DeWall, Ciarocco, \& Bartels, 2007; Twenge, Baumeister, Tice, \& Stucke, 2001). However, these bodies of literature can be reconciled by construing rejected individuals as guarded, social optimists who will lash out when reconnection is impossible but will affiliate when there is an opportunity to become reincluded (Maner et al., 2007; Sommer \& Bernieri, 2015). However, the neural and psychological processes that motivate individuals to affiliate, reconnect, and otherwise heal the interpersonal injury of rejection remain largely unknown.

\section{Social-physical pain overlap}

Social injuries, such as rejection, are associated with activation of the same neural substrates that underpin the affective component of physical pain (Eisenberger, 2012a, b, 2015; Rotge et al., 2015). Specifically, activation of both the dorsal anterior cingulate cortex (dACC) and the anterior insula have been reliably associated with social rejection (e.g., Chester et al., 2014; Eisenberger, 2015; Eisenberger, Gable, \& Lieberman, 2007; Eisenberger, Lieberman, \& Williams, 2003; Kawamoto et al., 2012). This well-replicated observation of neural pain signatures during rejection led to the coining of the term social pain, the aversive, affective response to social injury (Eisenberger \& Lieberman, 2004; MacDonald \& Leary, 2005).

Social pain can extend beyond affective pain regions of the brain to somatosensory regions during experiences of extreme rejection (i.e., recalling memories and viewing images of a recently estranged romantic partner; Kross, Berman, Mischel, Smith, \& Wager, 2011). Rejection activates the brain's endogenous opioid system to help cope with the resulting pain (Hsu et al., 2013, 2015). This overlap is further underscored by the ability of physical pain analgesics to reduce social pain (Deckman, DeWall, Way, Gilman, \& Richman, 2013; DeWall et al., 2010) and the shared genetic underpinning of physical and social pain sensitivity through the $\mu$-opioid receptor gene (OPRM-1; Slavich, Tartter, Brennan, \& Hammen, 2014; Way, Taylor, \& Eisenberger, 2009). In addition to the dACC, the ventral ACC has been shown to respond to social rejection, though this has been observed more frequently in adolescent samples and occurs later in rejection's timecourse, suggesting a regulatory function (Eisenberger, 2012a, b, 2015; Masten et al., 2009; Moor et al., 2012). This neural overlap extends to behavior as one's dispositional physical pain sensitivity predicts stronger, aversive reactions to rejection (Eisenberger, Jarcho, Lieberman, \& Naliboff, 2006) and inducing the experience of physical pain increases the distress of rejection (and vice-versa; Riva, Wirth, \& Williams, 2011; Wolf \& Davis, 2014). Taken together, there is a wealth of evidence that rejection is painful. Yet, why would social pain relate to the motivation for social connection after rejection?

\section{Pain and reparative behavior}

Physical pain is an adaptive response that indicates threat and motivates individuals to attend to the source of the pain (Bolles \& Fanselow, 1980; Chapman, 1995; Wall, 1999). Crucially, pain promotes reparative behaviors in response to injury, such as escaping the source of the injury, seeking social support, and increasing the hedonic value of healing behaviors (Bolles \& Fanselow, 1980; Bastian, Jetten, Hornsey, \& Leknes, 2014; Eccleston \& Crombez, 1999; Wall, 1999). As the physical pain increases in intensity, the degree of reparative behaviors increases in turn. Pain plays less of a role in motivating individuals to avoid sources of further harm, as this is largely the role of fear responses to injury (Bolles \& Fanselow, 1980). As such, fearful and avoidant responses to rejection are unlikely to be associated with social pain.

Given the anatomical and functional overlap between social and physical pain (Eisenberger, 2015), the impetus for reparative behavior may hold across both pain modalities. Thus, social pain should motivate healing behaviors that are intended to mend social injuries, such as those resulting from rejection. More specifically, social pain is likely to promote attempts at social reconnection with one's rejecters and connections with others, because these actions represent viable pathways to alleviating the threat of rejection. Indeed, after an instance of rejection, social pain is assuaged by subsequent, positive social interactions (e.g., Twenge et al., 2007). Thus, social pain is a plausible mediator of the social reconnection hypothesis (Maner et al., 2007).

\section{Present research}

Does social pain promote interpersonal reconnections? Study 1 tested the hypothesis that the social pain which resulted from an instance of rejection would predict a greater need for social reconnection. Using functional magnetic resonance imaging (fMRI), Study 2 tested the hypothesis that neural signatures of social pain would promote affiliative behavior toward the source of the rejection, as evidenced by seeking greater proximity toward them. 


\section{Study 1}

Study 1 tested whether social pain would promote a greater need for social reconnection following rejection. To do so, participants were either accepted or rejected, reported their current levels of somatic and social pain, and then reported their current need to belong. In line with the social reconnection hypothesis (Maner et al., 2007), we predicted that rejected individuals would report a greater need to belong. Furthermore, we predicted that the greater social pain reported by rejected participants would mediate this effect.

\section{Method}

\section{Participants}

Participants were 203 undergraduates (140 females; age: $M=$ $19.45, S D=2.08$ ). Participants were compensated with course credit for their participation.

\section{Measures}

McGill pain questionnaire - short form To measure participants' experience of social pain due to social rejection, participants completed a well-validated measure of both sensory and affective pain, the McGill Pain Questionnaire (Melzack, 1987). Previous research on social rejection has shown that social rejection increases reports of the affective subscale of this measure and have effectively used it as an index of social pain (e.g., Chen, Poon, Bernstein, \& Teng, 2014; Chen, Williams, Fitness, \& Newtown, 2008). This measure includes 15 adjectives regarding the subjective intensity of one's current pain levels, 0 (none) to 3 (severe). Eleven items measure sensory aspects of pain (e.g., shooting, stabbing) and four items measure affective components (e.g., fearful, punishing-cruel). Because social pain reflects the affective component of pain (Eisenberger, 2012a, b), this subscale was deemed an appropriate measure of social pain.

Need threat scale The 30 -item Need Threat Scale served as a multidimensional measure of the Cyberball paradigm's ability to elicit social pain and other associated forms of distress and threat (Williams, 2009). Aside from a two-item "felt rejection" measure that serves as a manipulation check (sample item: "I was excluded"), the Need Threat Scale also contains four, five-item subscales that assess the extent to which rejection threatened the human needs for belonging, self-esteem, control, and meaningful existence and an eightitem subscale that measures subsequent negative affect. Participants responded to each item along a 5-point Likerttype scale, with higher values representing greater degrees of each subscale's latent construct.
Need to belong scale To measure participants' motivations for social connection, we administered the 10-item Need to Belong Scale (Leary, Kelly, Cottrell, \& Schreindorfer, 2013). This reliable and well-validated measure assesses individual differences in the desire to be accepted by others by having participants endorse statements about themselves (sample items: "I want other people to accept me" and "I try hard not to do things that will make other people avoid or reject me") along a 5-point Likert-type scale. To assess state levels of the need to belong, a prompt appeared prior to the survey that instructed participants to respond to each item as they felt "right now and not in general." After reverse scoring the appropriate items, responses from all 10 items were averaged to create an overall index of the need to belong, with higher values representing greater need to belong. Need-to-belong scores show divergent validity from similar, correlated constructs, such as extraversion (Leary et al., 2013).

\section{Procedure}

Participants arrived at our laboratory and were told that they would be practicing their mental visualization skills via an online ball-tossing game called Cyberball, which actually served to induce experiences of social acceptance and rejection (Version 3.0; Williams et al., 2000; Williams \& Jarvis, 2006). Participants believed that they played this game over the Internet with two, same-sex undergraduates who were in nearby testing rooms. By random assignment, 102 participants received an equal amount of throws (i.e., $\sim 33 \%$; acceptance condition), and 107 participants stopped receiving the ball after approximately 2 minutes of inclusion (i.e., rejection condition). Then, participants completed the Need Threat Scale (NTS), McGill Pain Questionnaire (MPQ), and the Need to Belong Scale (NTB). After these procedures, all participants received a suspicion probe and were debriefed. No participants indicated enough suspicion to exclude them from analysis.

\section{Results}

Due to experimenter error, MPQ and NTS data were missing from four participants, leaving full data from 199 participants. Scores from the NTS's felt-rejection manipulation check, the MPQ, and the NTB scales showed sufficient reliability, $\alpha \mathrm{s}=$ .81 - .96. Zero-order correlations between the MPQ subscales, the NTS subscales, and the NTB scale are described in Table 1.

Confirming our social rejection manipulation's efficacy, rejected participants reported greater feelings of being rejected, $M=3.86, S D=1.13$, than their accepted counterparts, $M=1.53, S D=0.91$, on the two-item manipulation check, $t(197)=16.43, p<.001$. Participants also reported 
Table 1 Zero order correlations between the measures included in Study 1

\begin{tabular}{|c|c|c|c|c|c|c|c|c|}
\hline & 1 & 2 & 3 & 4 & 5 & 6 & 7 & 8 \\
\hline \multicolumn{9}{|l|}{ 1. MPQ-Affective } \\
\hline 2. MPQ-Sensory & $.68 * * *$ & & & & & & & \\
\hline 3. Need to Belong & -.01 & $-.17 *$ & & & & & & \\
\hline 4. NTS-Belonging Threat & .10 & .01 & .11 & & & & & \\
\hline 5. NTS-Control Threat & -.01 & -.09 & $.15^{*}$ & $.79 * * *$ & & & & \\
\hline 6. NTS-Felt Rejection & .01 & -.11 & .08 & $.85 * * *$ & $.75^{* * *}$ & & & \\
\hline 7. NTS-Meaning Threat & .11 & -.04 & .11 & $.86^{* * *}$ & $.80 * * *$ & $.81^{* * *}$ & & \\
\hline 8. NTS-Negative Affect & .07 & -.05 & $.16^{*}$ & $.76 * * *$ & $.69 * * *$ & $.69 * * *$ & $.80 * * *$ & \\
\hline 9. NTS-Self-Esteem Threat & .09 & -.06 & .11 & $.80 * * *$ & $.77 * * *$ & $.70^{* * *}$ & $.82 * * *$ & $.84 * * *$ \\
\hline
\end{tabular}

${ }^{*} p<.05 .{ }^{* *} p<.001$

greater threat to needs for belongingness, control, meaningful existence, and self-esteem, all $t \mathrm{~s}>11.68$, all $p \mathrm{~s}<.001$. We controlled for participants' somatosensory pain levels in our mediation model, as previous research has demonstrated that rejection increases physical pain, though to a lesser extent than social pain (Kross et al., 2011; Riva et al., 2011; Wolf \& Davis, 2014). After controlling for scores on the sensory subscale of the MPQ, rejected participants reported greater social pain as measured by the affective subscale of the MPQ, $F(1$, $196)=4.20, p=.042, \eta_{\mathrm{p}}{ }^{2}=.021$. Suggesting an indirect effect, social pain was associated with a greater need to belong, $\beta=.20, t(196)=2.15, p=.033$, after controlling for sensory pain levels. Using a bias-corrected, bootstrapped mediation analysis (1,000 samples; Preacher \& Hayes, 2008), we found that rejection (coded as 1 for rejected and 0 for accepted) exhibited an indirect effect on a greater need to belong through social pain reports while controlling for sensory pain (95\% confidence interval: .001, .089; adjusted $R^{2}=.04$; see Fig. 1).

\section{Discussion}

Study 1 replicated the typically observed social pain effect where rejected participants report experiencing more social pain. Supporting our prediction, this greater social pain went on to predict a greater need for social reconnection. These findings suggest that the pain of rejection pushes individuals toward others. Unexpectedly, we did not observe a direct effect of rejection on a greater need to belong. The indirect effect that we did observe underscores social pains' crucial role in postrejection motivations for social connections. However, it remains unknown whether (a) social pain would predict actual increases in behaviors aimed at reconnecting and (b) whether neural measures of social pain would predict such affiliative behaviors. Study 2 was conducted to test both of these possibilities.

\section{Study 2}

Study 2 expanded upon Study 1 by (a) focusing on affiliative behaviors instead of self-reports, and (b) using a neural measure of social pain instead of self-reports. This study was part of a larger effort to explore social pain's relation to both affiliative and aggressive responses to rejection. To do so, participants experienced social acceptance and then rejection from the same two people while undergoing functional neuroimaging (fMRI), were given an opportunity to aggress against one of their rejecters, and then were given an opportunity to affiliate with their other rejecter through interpersonal proximity. Social pain's association with aggressive behavior is reported in another manuscript (Chester et al., 2014), and the aggression data is excluded from this manuscript for several reasons. First, aggressive and affiliative behaviors are increasingly viewed as distinct phenomena, not polar opposites (Krueger, Hicks, \& McGue, 2001; McGinley \& Carlo, 2007). Indeed, from punishing one's children to suicide bombings, antisocial and prosocial acts are often difficult to delineate (Tobeña, 2009). Second, executive functioning was thought to play a critical role in aggressive, but not affiliative, responses to rejection (Chester et al., 2014; Riva, RomeroLauro, DeWall, Chester, \& Bushman, 2015); thus, our

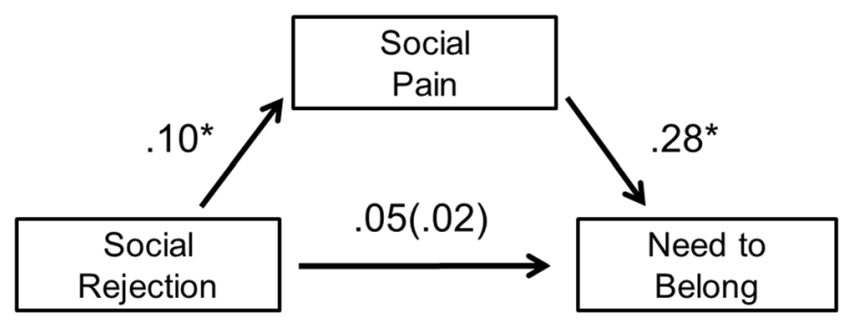

Fig. 1 Bootstrapped mediation model whereby self-reported social pain mediated the effect of rejection on the greater need to belong. Values represent unstandardized regression coefficients. Parenthesized value represents the direct effect after controlling for the indirect effect (i.e., c' path). ${ }^{*} p<.05$ 
predictions were substantially different regarding aggressive and affiliative outcomes.

The sample size of Study 2 is substantially reduced from that of Study 1 due to the logistical constraints of functional neuroimaging. However, statistical modeling has shown that such samples sizes $(N=28)$ can readily yield replicable and valid inferences regarding neural functioning and its relation to behavior (Lieberman, Berkman, \& Wager, 2009).

\section{Method}

\section{Participants}

Participants were 28 healthy, right-handed undergraduate students who received course credit and money in compensation for their participation (17 females; age: $M=18.96, S D=$ 1.51). ${ }^{1}$ Participants were screened for metallic objects in their body, psychoactive medication use, psycho- or neuropathologies, claustrophobia, seizure tendencies, suspected pregnancy, and body mass indices under 30 (i.e., the obesity cutoff).

\section{Procedure}

Participants arrived at our neuroimaging laboratory where they were screened for safe entry into the fMRI environment. Participants were told that they would be playing an online ball-tossing game called Cyberball with two same-sex undergraduates while they all simultaneously underwent fMRI. Then, participants completed a version of the Cyberball task that was adapted for the parameters of fMRI to induce first an experience of social acceptance and then rejection with the same two partners (as in Chester et al., 2014). The task was divided into three 60 -second blocks, with a 12 -second interblock rest interval. In the first 2.5 blocks, participants received the ball an equal number of times ( $33 \%$; acceptance condition). However, for the second half of the third block (30 second duration), participants did not receive the ball (rejection condition).

After a series of anatomical and other scans, participants were removed from the scanner and placed in an adjoining room. Participants then completed an aggression task against one of their two Cyberball partners (as presented in Chester et al., 2014). They were unable to choose which of the two partners to complete these tasks with. After the aggression measure, participants were given an opportunity to reconnect with the other partner from Cyberball. To measure this, we employed a simplified version of Macrae, Bodenhausen, Milne, and Jetten's (1994) social distance paradigm (as used

\footnotetext{
${ }^{1}$ These neural data, combined with the data of other participants who did not complete the chair task, are reported in two other papers (Chester et al., 2014; Chester, Pond, \& DeWall, 2015).
}

by Buck, Ashby, Ratcliff, Zielaskowski, \& Boerner, 2013; Vohs, Meade, \& Goode, 2006). The use of interpersonal proximity-seeking as a measure of desired social reconnection has been effectively used in previous research on social rejection and subsequent affiliative responses (Sommer \& Bernieri, 2015). Participants were told that they would soon be having a brief, "getting to know each other" conversation with the Cyberball partner they had yet to interact with. Then, participants were asked to position two chairs to face each other in the center of the room and have a seat in one of the chairs while the experimenter left the room to retrieve participants' fictitious partner. After 90 seconds, the experimenter returned, asked the participant to stay still in their chair and then used a measuring tape to record the distance (in 1/20-inch increments) between the front legs of the two chairs. The experiment then concluded and participants were fully debriefed.

\section{FMRI data acquisition parameters}

All images were collected on a $3 \mathrm{~T}$ Siemens Magnetom Trio scanner. Functional images were acquired with a T2*-weighted gradient echo sequence with the following parameters: 2.5 s repetition time, 28 -ms echo time, $64 \times 64$ matrix, $224 \times 224$ $\mathrm{mm}$ field of view, forty $3.5-\mathrm{mm}$ axial slices acquired in interleaved order. A 3-D shim was applied before functional data acquisition. These parameters allowed for whole brain coverage with 3.5-mm cubic voxels. A high-resolution, T1weighted image was also acquired from each participant so that functional data could be registered to native anatomical space and then normalized to the Montreal Neurological Institute (MNI) atlas space.

\section{FMRI data preprocessing and analysis}

All preprocessing and statistical analyses of fMRI data were conducted using FSL (Oxford Center for Functional Magnetic Resonance Imaging; Jenkinson, Beckmann, Behrens, Woolrich, \& Smith, 2012; Smith et al., 2004). Functional volumes were corrected for head movement to the median volume using MCFLIRT, corrected for slice-timing skew using temporal sinc interpolation, prewhitened using FILM, and smoothed with a 5-mm FWHM Gaussian kernel. To remove drifts within sessions, a high-pass filter with a cutoff period of $120 \mathrm{~s}$ was applied. Nonbrain structures were stripped from functional and anatomical volumes using FSL's Brain Extraction Tool.

FMRI analysis was performed using FSL's FMRI Expert Analysis Tool (FEAT Version 5.98). A fixed-effects analysis modeled event-related responses for each run of each participant. Acceptance and rejection blocks were modeled as events using a canonical double-gamma hemodynamic response function with a temporal derivative. Rest blocks were left unmodeled. The contrast of interest was Rejection $>$ 
Acceptance. Functional volumes and first-level contrast images from this analysis were first registered to corresponding structural volumes using 7 degrees of freedom, and then spatially normalized to an MNI stereotaxic space template image using 12 degrees of freedom with FMRIB's Linear Image Registration Tool (FLIRT). FMRIB's Local Analysis of Mixed Effects module (FLAME) was used to perform toplevel, mixed-effects analysis, which created group average maps for contrasts of interest. $Z$ (Gaussianized T/F) statistic images were thresholded using clusters determined by $Z>2.3$ and a family-wise error corrected (via Gaussian Random Field) cluster significance threshold of $p<.005$ in an a priori regions-of-interest (ROIs; Heller, Stanley, Yekutieli, Rubin, \& Benjamini, 2006; Worsley, 2001). ROIs of the dACC and anterior insula were created by Way and colleagues (2009) from the automated anatomical atlas (AAL) using MNI coordinates (Tzourio-Mazoyer et al., 2002). The dACC ROI used a rostral boundary of $y=33$ and a caudal boundary of $y=0$. The anterior insula ROIs used a caudal boundary of $y=8$ to correspond to the agranular insula.

\section{Results}

Social rejection, compared to social acceptance, was associated with increased activity in the dACC and bilateral anterior insula (see Fig. 2a-b; Table 2).

Functional data from the activated main effect clusters from our contrast-of-interest were converted to units of percent signal change, averaged across each participant and separately extracted from the $\mathrm{dACC}$, and left and right anterior insula (as outlined by Mumford, n.d.).

Chair distance ranged from 16.5 inches to 43.0 inches $(M=$ $30.51, S D=7.33)$. Chair distance was significantly negatively correlated with percent signal change units from the dACC, $r(26)=-.39, p=.043$, left anterior insula, $r(26)=-.44, p=$ .019 , and marginally negatively correlated with activation of the right anterior insula, $r(26)=-.33, p=.088$ (see Fig. 2c-e). Thus, greater activity in the $\mathrm{dACC}$ and anterior insula in response to social exclusion was associated with greater proximity toward rejecters.

\section{Discussion}

Study 2 replicated the effect of rejection (as compared to acceptance) on increased activity in the dACC, and bilateral anterior insula (Eisenberger et al., 2003). Activity in each of these three regions then predicted more affiliative behaviors as represented by greater proximity between the participant and their rejecter. These findings lend further support to our assertion that social pain promotes affiliative behavior and healing of social injuries. The study was limited in that the aggression measure preceded the chair proximity task. Thus, participants' aggressive acts might have altered their behavior on the chair proximity task, possibly due to some mood-reparative function. However, aggressive acts bias individuals toward further aggression (Bushman, 2002) and the aggression measure may have blunted participants' affiliative tendencies. It is impressive that even after acting aggressively, most participants in Study 2 were still willing to indicate some attempts at affiliative reconnection.

\section{General discussion}

Social rejection evokes strong responses. When individuals feel there is no opportunity to heal their recently incurred social injury, they often lash out (Twenge et al., 2001). Conversely, when rejected people perceive an opportunity to mend the broken social bond, they seek to reconnect (DeWall \& Richman, 2011; Maner et al., 2007; Watson-Jones et al., 2016). Understanding the mechanisms behind social reconnection is a crucial task, both to understand social rejection and to promote affiliative responses over aggressive ones. Across two studies, we tested the proposal that the pain of rejection promotes attempts at healing the social injury.

In Study 1, rejection increased individual's levels of emotional pain, which then predicted their reported motivation to seek reconnection. In this sense, reconnection is a true form of social healing as an injured social bond is repaired. Although this finding suggests that the pain of rejection motivates others to seek social connections to heal the social injury, it did not explore whether social pain predicts changes in actual behavior. Therefore, we observed in Study 2 that social pain, as indicated by neural activity in the $\mathrm{AACC}$ and anterior insula, predicted greater attempts at interpersonal closeness, a proxy for social reconnection. Across both of these studies, we observed support for social pain overlap theory (Eisenberger \& Lieberman, 2004; MacDonald \& Leary, 2005) in that rejection caused increases in measures of pain. We found support for this across both self-report and neural measures, which reifies the proposal that neural signatures of social pain are valid indicators of the anguish of exclusion. More generally, our findings add another way in which physical and social pain overlap: that they both promote healing of injuries within their respective domains.

Despite the overlap between somatosensory and social pain, we observed some interesting differences. In Study 1, social pain only mediated the effect of rejection on the need to belong when we statistically controlled for the effect of somatosensory pain. Furthermore, somatosensory pain (which was highly correlated with social pain) was slightly negatively correlated with the need to belong, whereas social pain was positively correlated with it. These divergent associations with the desire for social reconnection reflect the different 
A

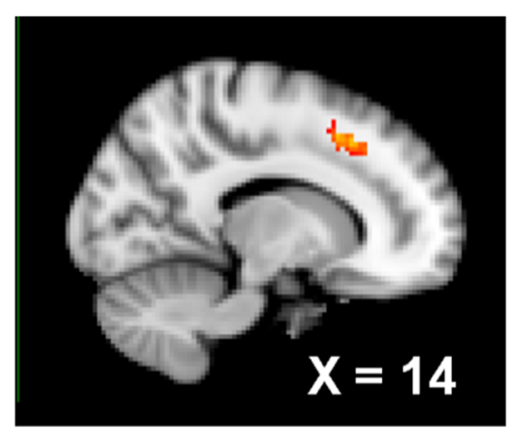

B

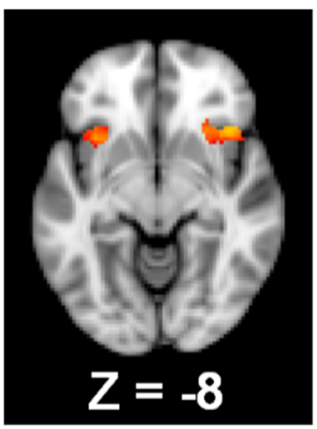

$Z=4.85$

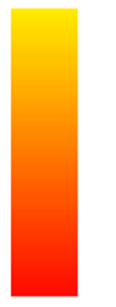

$Z=2.3$
C

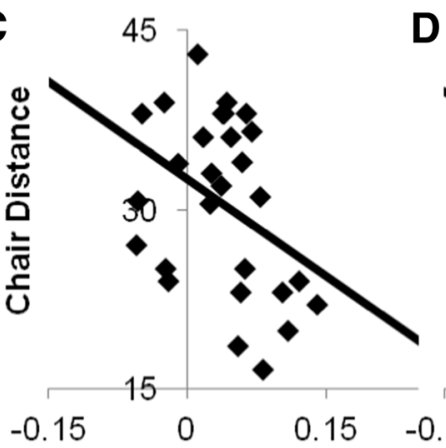

D 45

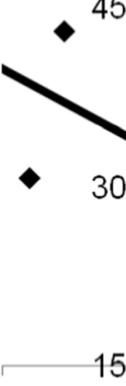

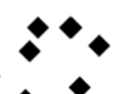

E
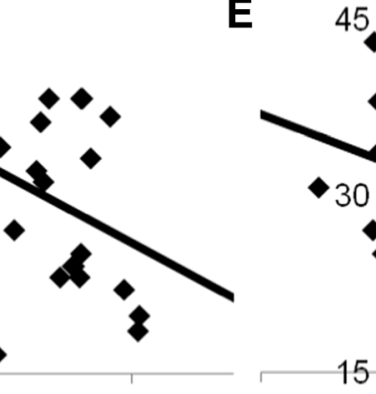

0.15

$-0.15$

$\%$ Signal Change

Fig. 2 a dACC and $\mathbf{b}$ anterior insula activation associated with Rejection $>$ Acceptance in MNI space. $\mathbf{c}$ dACC, $\mathbf{d}$ left and $\mathbf{e}$ right anterior insula activation associated with Rejection $>$ Acceptance as they negatively correlate with chair distance (in inches) from the reconnection task

functional attributes of these two forms of pain. Somatosensory pain is reliably associated with avoidant behaviors such as social withdrawal (e.g., Kashikar-Zuck et al., 2007), whereas social pain arises in the dACC, which is known to harness its 'alarm' function during rejection to motivate approach-related behaviors (e.g., Chester et al., 2014). As such, there is good reason to have observed that somatosensory and social pain were differentially associated with the need to belong.

There exist some challenges to the proposal that social rejection is truly painful and that the dACC activity observed during rejection is unreliable or due to a nonpainful psychological process (Cacioppo et al., 2013; Iannetti, Salomons, Moayedi, Mouraux, \& Davis, 2013; Woo et al., 2014). However, meta-analytic and other neuroimaging evidence establishes that the $\mathrm{dACC}$ is reliably associated with rejection

Table 2 Brain regions-of-interest associated with Rejection > Acceptance

\begin{tabular}{llll}
\hline & $\begin{array}{l}\text { contiguous } \\
\text { voxels }\end{array}$ & $\begin{array}{l}\text { peak } \\
Z\end{array}$ & $\begin{array}{l}\text { peak MNI } \\
\text { coordinates } \\
(\mathrm{x}, \mathrm{y}, \mathrm{z})\end{array}$ \\
\hline dACC & 291 & 4.29 & $16,22,44$ \\
anterior insula & 535 & 4.85 & $42,24,0$ \\
& 344 & 4.58 & $-34,16,-18$ \\
\hline
\end{tabular}

and pain and not with other processes such as conflictmonitoring or salience (Eisenberger, 2015; Kawamoto et al., 2012; Lieberman \& Eisenberger, 2015; Rotge et al., 2015). Given this wealth of supporting evidence, the proposal that rejection is truly painful is well-founded.

It remains unknown how our findings would be moderated by the intensity of social pain. Our manipulation of social pain was relatively moderate and chosen because previous research has indicated that the Cyberball task elicits acute levels of social pain that go on to alter various behaviors and motives (Bernstein \& Claypool, 2012). However, other manipulations can induce such strong and seemingly immutable levels of social pain that individuals respond with numbness and a lack of motivation (Bernstein \& Claypool). Future research might benefit from exploring the level of intensity that most motivates affiliative behaviors. Other psychological processes such as anger, anxiety, empathy, and fear may also play substantial roles in why rejected individuals act in aggressive and affiliative ways. More research is needed to delineate a taxonomy of the proximal mechanisms of postrejection behavior.

The Cyberball task we utilized has features of ostracism that are more akin to being passively ignored than by being actively rejected (e.g., someone saying "I do not want you to participate in this group"), another form of ostracism. Rejection tends to promote active and approach-based tendencies, whereas being ignored promotes passive and avoidantbased tendencies (Molden, Lucas, Gardner, Dean, \& 
Knowles, 2009). Future research would benefit from exploring whether being actively rejected results in proximity seeking or more avoidant behaviors.

Yet, how can social pain promote affiliation when previous research has linked it to aggression (Chester et al., 2014)? First, the link between social pain and greater aggression has only been observed among individuals lower in executive functioning. Among individuals high in executive functioning, social pain was linked to lesser aggression, and there was no main effect of social pain on aggressive behavior. Conversely, we observed significant main effects of social pain on postrejection reconnective behaviors, which may suggest that the self-regulatory capabilities are not necessary to convert social pain into attempts at social reconnection. Indeed, these findings fit with theories that posit that affiliative and prosocial behaviors are largely automatic and do not require self-regulation (Preston \& de Waal, 2002). Second, it is likely that social pain simultaneously promotes both aggressive and affiliative tendencies, and which tendency translates to behavior is determined by which behavior is possible in the situation. When you are able to administer noise blasts to your rejecter, social pain promotes aggression (Chester et al., 2014), yet when you can engage in a friendly exercise, you seek to reconnect. These competing motives speak to the dynamic functions of pain, which can yield both beneficial and maladaptive outcomes. Finally, aggression and affiliation appear to be distinct behavioral modalities (Krueger et al., 2001; McGinley \& Carlo, 2007). Thus, social pain likely plays unique and nuanced roles in antisocial and prosocial outcomes.

Our findings were limited in several ways. Study 1 used a measure of the need to belong, which did not distinguish between the desire to connect with new partners or with one's rejecters. Therefore, we cannot know whether social pain promotes one of those options or both. We cannot be sure that Study 2's measure of interpersonal proximity represented affiliative motives as aggression also promotes proximity seeking. However, the chair task has a long history of being used to measure purely prosocial motivations. For instance, in previous research, chair proximity was reduced among undesirable social connection partners (i.e., those from negatively stereotyped groups; Buck et al., 2013; Macrae et al., 1994) and after experimental primes that typically increase aggressive behavior (i.e., money; Vohs et al., 2006). Thus, it is highly unlikely that chair proximity represented aggressive, antisocial motivations. Also, we interpreted the activity in the dACC and anterior insula to signify the presence of social pain, which relies upon the potentially problematic practice of reverse inference (Poldrack, 2006). Finally, participants only completed our proximity task with their rejecters, not novel individuals. The use of participants' rejecters was a conservative test of our hypothesis, as research has shown that individuals are more prone toward reconnecting with novel interaction partners than their rejecters (Maner et al., 2007). As such, it is likely that our findings from Study 2 would be even more pronounced if targets were novel interaction partners.

Despite these limitations, our findings may suggest practical applications. If social pain can promote affiliative responses to rejection, it may be that interventions targeting the reduction of postrejection aggression might harness social pain's motivational capacities to translate aggressive tendencies into affiliative ones. This putative motivational role of social pain provides a mechanistic and parsimonious account of how rejection can lead to socially reparative responses due to the dynamic functions of pain.

Acknowledgments We are sincerely grateful to Naomi Eisenberger for her assistance with earlier iterations of this manuscript, for providing Study 2's Cyberball task, and guidance throughout this project. This experiment was funded by grants to the second author from the National Institute on Drug Abuse (Grant number: DA005312) and the National Science Foundation (Grant number: BCS1104118).

\section{References}

Balliet, D., \& Ferris, D. L. (2013). Ostracism and prosocial behavior: A social dilemma perspective. Organizational Behavior and Human Decision Processes, 120(2), 298-308.

Bastian, B., Jetten, J., Hornsey, M. J., \& Leknes, S. (2014). The positive consequences of pain: A biopsychosocial approach. Personality and Social Psychology Review, 18(3), 256-279.

Baumeister, R. F., \& Leary, M. R. (1995). The need to belong: Desire for interpersonal attachments as a fundamental human motivation. Psychological Bulletin, 117(3), 497-529.

Bernstein, M. J., \& Claypool, H. M. (2012). Social exclusion and pain sensitivity: Why exclusion sometimes hurts and sometimes numbs. Personality and Social Psychology Bulletin, 38(2), 185-196.

Bolles, R. C., \& Fanselow, M. S. (1980). A perceptual-defensiverecuperative model of fear and pain. Behavioral and Brain Sciences, 3(02), 291-301.

Buck, D. M., Ashby, E., Ratcliff, J., Zielaskowski, K., \& Boerner, P. (2013). Concern over the misidentification of sexual orientation: Social contagion and the avoidance of sexual minorities. Journal of Personality and Social Psychology, 105(6), 941-960.

Bushman, B. J. (2002). Does venting anger feed or extinguish the flame? Catharsis, rumination, distraction, anger, and aggressive responding. Personality and Social Psychology Bulletin, 28(6), 724-731.

Cacioppo, S., Frum, C., Asp, E., Weiss, R. M., Lewis, J. W., \& Cacioppo, J. T. (2013). A quantitative meta-analysis of functional imaging studies of social rejection. Scientific Reports, 3, 2027. doi:10.1038/ srep02027

Chapman, C. R. (1995). The affective dimension of pain: A model. In B. Bromm \& J. E. Desmedt (Eds), Pain and the brain: from nociception to cognition. (Vol. 22, pp. 283-301). New York: Raven Press.

Chen, Z., Poon, K.-T., Bernstein, M. J., \& Teng, F. (2014). Rejecting another pains the self: The impact of perceived future rejection. Journal of Experimental Social Psychology, 50, 225-233.

Chen, Z., Williams, K. D., Fitness, J., \& Newton, N. C. (2008). When hurt will not heal exploring the capacity to relive social and physical pain. Psychological Science, 19(8), 789-795. 
Chester, D. S., Eisenberger, N. I., Pond, R. S., Richman, S. B., Bushman, B. J., \& DeWall, C. N. (2014). The interactive effect of social pain and executive functioning on aggression: An fMRI experiment. Social Cognitive and Affective Neuroscience, 9(5), 699-704.

Chester, D. S., Pond, R. S., \& DeWall, C. N. (2015). Alexithymia is associated with blunted anterior cingulate response to social rejection: Implications for daily rejection. Social Cognitive and Affective Neuroscience, 10(4), 517-522.

Deckman, T., DeWall, C. N., Way, B., Gilman, R., \& Richman, S. (2013). Can marijuana reduce social pain? Social Psychological and Personality Science, 5(2), 131-139.

DeWall, C. N. (2010). Forming a basis for acceptance: Excluded people form attitudes to agree with potential affiliates. Social Influence, 5(4), 245-260.

DeWall, C. N., MacDonald, G., Webster, G. D., Masten, C. L., Baumeister, R. F., Powell, C., ... \& Eisenberger, N. I. (2010). Acetaminophen reduces social pain behavioral and neural evidence. Psychological Science, 21(7), 931-937.

DeWall, C. N., Maner, J. K., \& Rouby, D. A. (2009). Social exclusion and early-stage interpersonal perception: Selective attention to signs of acceptance. Journal of Personality and Social Psychology, 96(4), 729-741.

DeWall, C. N., \& Pond, R. S. (2011). Loneliness and smoking: The costs of the desire to reconnect. Self and Identity, 10(3), 375-385.

DeWall, C. N., \& Richman, S. B. (2011). Social exclusion and the desire to reconnect. Social and Personality Psychology Compass, 5(11), 919-932.

Eccleston, C., \& Crombez, G. (1999). Pain demands attention: A cognitive-affective model of the interruptive function of pain. Psychological Bulletin, 125(3), 356-366.

Eisenberger, N. I. (2012a). Broken hearts and broken bones: A neural perspective on the similarities between social and physical pain. Current Directions in Psychological Science, 21(1), 42-47.

Eisenberger, N. I. (2012b). The pain of social disconnection: Examining the shared neural underpinnings of physical and social pain. Nature Reviews Neuroscience, 13(6), 421-434.

Eisenberger, N. I. (2013). Social ties and health: A social neuroscience perspective. Current Opinion in Neurobiology, 23(3), 407-413.

Eisenberger, N. I. (2015). Social pain and the brain: Controversies, questions, and where to go from here. Annual Review of Psychology, 66(1), 601-629.

Eisenberger, N. I., Gable, S. L., \& Lieberman, M. D. (2007). Functional magnetic resonance imaging responses relate to differences in realworld social experience. Emotion, 7(4), 745-754.

Eisenberger, N. I., Jarcho, J. M., Lieberman, M. D., \& Naliboff, B. D. (2006). An experimental study of shared sensitivity to physical pain and social rejection. Pain, 126(1), 132-138.

Eisenberger, N. I., \& Lieberman, M. D. (2004). Why rejection hurts: A common neural alarm system for physical and social pain. Trends in Cognitive Sciences, 8(7), 294-300.

Eisenberger, N. I., Lieberman, M. D., \& Williams, K. D. (2003). Does rejection hurt? An fMRI study of social exclusion. Science, 302(5643), 290-292.

Heller, R., Stanley, D., Yekutieli, D., Rubin, N., \& Benjamini, Y. (2006). Cluster-based analysis of FMRI data. NeuroImage, 33(2), 599-608.

Hsu, D. T., Sanford, B. J., Meyers, K. K., Love, T. M., Hazlett, K. E., Walker, S. J., ... Zubieta, J.-K. (2015). It still hurts: Altered endogenous opioid activity in the brain during social rejection and acceptance in major depressive disorder. Molecular Psychiatry, 20(2), 193-200.

Hsu, D. T., Sanford, B. J., Meyers, K. K., Love, T. M., Hazlett, K. E., Wang, H., ... \& Zubieta, J. K. (2013). Response of the $\mu$-opioid system to social rejection and acceptance. Molecular Psychiatry, 18(11), 1211-1217.
Iannetti, G. D., Salomons, T. V., Moayedi, M., Mouraux, A., \& Davis, K. D. (2013). Beyond metaphor: Contrasting mechanisms of social and physical pain. Trends in Cognitive Sciences, 17(8), 371-378.

Jenkinson, M., Beckmann, C. F., Behrens, T. E., Woolrich, M. W., \& Smith, S. M. (2012). FSL. NeuroImage, 62, 782-790.

Kashikar-Zuck, S., Lynch, A. M., Graham, T. B., Swain, N. F., Mullen, S M., \& Noll, R. B. (2007). Social functioning and peer relationships of adolescents with juvenile fibromyalgia syndrome. Arthritis Care \& Research, 57(3), 474-480.

Kawamoto, T., Onoda, K., Nakashima, K., Nittono, H., Yamaguchi, S., \& Ura, M. (2012). Is dorsal anterior cingulate cortex activation in response to social exclusion due to expectancy violation? An fMRI study. Frontiers in Evolutionary Neuroscience, 4, 11. doi:10.3389/ fnevo.2012.00011

Kross, E., Berman, M. G., Mischel, W., Smith, E. E., \& Wager, T. D. (2011). Social rejection shares somatosensory representations with physical pain. Proceedings of the National Academy of Sciences, 108(15), 6270-6275.

Krueger, R. F., Hicks, B. M., \& McGue, M. (2001). Altruism and antisocial behavior: Independent tendencies, unique personality correlates, distinct etiologies. Psychological Science, 12(5), 397-402.

Leary, M. R., Kelly, K. M., Cottrell, C. A., \& Schreindorfer, L. S. (2013). Construct validity of the need to belong scale: Mapping the nomological network. Journal of Personality Assessment, 95(6), 610 624.

Lieberman, M. D., Berkman, E. T., \& Wager, T. D. (2009). Correlations in social neuroscience aren't voodoo: Commentary on Vul et al. (2009). Perspectives on Psychological Science, 4(3), 299-307.

Lieberman, M. D., \& Eisenberger, N. I. (2015). The dorsal anterior cingulate cortex is selective for pain: Results from large-scale reverse inference. Proceedings of the National Academy of Sciences, $112(49), 15250-15255$.

MacDonald, G., \& Leary, M. R. (2005). Why does social exclusion hurt? The relationship between social and physical pain. Psychological Bulletin, 131(2), 202-223.

Macrae, C. N., Bodenhausen, G. V., Milne, A. B., \& Jetten, J. (1994). Out of mind but back in sight: Stereotypes on the rebound. Journal of Personality and Social Psychology, 64, 808-817.

Maner, J. K., DeWall, C. N., Baumeister, R. F., \& Schaller, M. (2007). Does social exclusion motivate interpersonal reconnection? Resolving the "porcupine problem.". Journal of Personality and Social Psychology, 92(1), 42-55.

Masten, C. L., Eisenberger, N. I., Borofsky, L. A., Pfeifer, J. H., McNealy, K., Mazziotta, J. C., \& Dapretto, M. (2009). Neural correlates of social exclusion during adolescence: Understanding the distress of peer rejection. Social Cognitive and Affective Neuroscience, 4(2), $143-157$.

McGinley, M., \& Carlo, G. (2007). Two sides of the same coin? The relations between prosocial and physically aggressive behaviors. Journal of Youth and Adolescence, 36(3), 337-349.

Mead, N. L., Baumeister, R. F., Stillman, T. F., Rawn, C. D., \& Vohs, K. D. (2011). Social exclusion causes people to spend and consume strategically in the service of affiliation. Journal of Consumer Research, 37(5), 902-919.

Melzack, R. (1987). The short-form McGill Pain Questionnaire. Pain, 30(2), 191-197.

Molden, D. C., Lucas, G. M., Gardner, W. L., Dean, K., \& Knowles, M. L. (2009). Motivations for prevention or promotion following social exclusion: Being rejected versus being ignored. Journal of Personality and Social Psychology, 96(2), 415-431.

Moor, B. G., Güroğlu, B., Op de Macks, Z. A., Rombouts, S. A. R. B., Van der Molen, M. W., \& Crone, E. A. (2012). Social exclusion and punishment of excluders: Neural correlates and developmental trajectories. NeuroImage, 59(1), 708-717.

Mumford, J. (n.d.). A guide to calculating percent change with Featquery. Available from http://mumford.fmripower.org/perchange_guide.pdf 
Poldrack, R. A. (2006). Can cognitive processes be inferred from neuroimaging data? Trends in Cognitive Sciences, 10(2), 59-63.

Preacher, K. J., \& Hayes, A. F. (2008). Asymptotic and resampling strategies for assessing and comparing indirect effects in multiple mediator models. Behavior Research Methods, 40(3), 879-891.

Preston, S. D., \& de Waal, F. B. M. (2002). Empathy: Its ultimate and proximate bases. Behavioral and Brain Sciences, 25(01), 1-20.

Riva, P., Romero-Lauro, L. J., DeWall, C. N., Chester, D. S., \& Bushman, B. J. (2015). Reducing aggressive responses to social exclusion using transcranial direct current stimulation (tDCS). Social Cognitive and Affective Neuroscience, 10(3), 352-356.

Riva, P., Wirth, J. H., \& Williams, K. D. (2011). The consequences of pain: The social and physical pain overlap on psychological responses. European Journal of Social Psychology, 41(6), 681-687.

Romero-Canyas, R., Downey, G., Reddy, K. S., Rodriguez, S., Cavanaugh, T. J., \& Pelayo, R. (2010). Paying to belong: When does rejection trigger ingratiation? Journal of Personality and Social Psychology, 99(5), 802-823.

Rotge, J.-Y., Lemogne, C., Hinfray, S., Huguet, P., Grynszpan, O., Tartour, E., ... Fossati, P. (2015). A meta-analysis of the anterior cingulate contribution to social pain. Social Cognitive and Affective Neuroscience, 10(1), 19-27.

Slavich, G. M., Tartter, M. A., Brennan, P. A., \& Hammen, C. (2014). Endogenous opioid system influences depressive reactions to socially painful targeted rejection life events. Psychoneuroendocrinology, 49, 141-149.

Smith, S. M., Jenkinson, M., Woolrich, M. W., Beckmann, C. F., Behrens, T. E. J., Johansen-Berg, H., ... Matthews, P. M. (2004). Advances in functional and structural MR image analysis and implementation as FSL. NeuroImage, 23(Suppl. 1), S208-S219.

Sommer, K. L., \& Bernieri, F. (2015). Minimizing the pain and probability of rejection evidence for relational distancing and proximity seeking within face-to-face interactions. Social Psychological and Personality Science, 6(2), 131-139.

Tobeña, A. (2009). Lethal altruists. Annals of the New York Academy of Sciences, 1167(1), 5-15.

Twenge, J. M., Baumeister, R. F., DeWall, C. N., Ciarocco, N. J., \& Bartels, J. M. (2007). Social exclusion decreases prosocial behavior. Journal of Personality and Social Psychology, 92(1), 56-66.

Twenge, J. M., Baumeister, R. F., Tice, D. M., \& Stucke, T. S. (2001). If you can't join them, beat them: Effects of social exclusion on aggressive behavior. Journal of Personality and Social Psychology, 81(6), 1058-1069.
Twenge, J. M., Zhang, L., Catanese, K. R., Dolan-Pascoe, B., Lyche, L. F., \& Baumeister, R. F. (2007). Replenishing connectedness: Reminders of social activity reduce aggression after social exclusion. British Journal of Social Psychology, 46(1), 205-224.

Tzourio-Mazoyer, N., Landeau, B., Papathanassiou, D., Crivello, F., Etard, O., Delcroix, N., ... Joliot, M. (2002). Automated anatomical labeling of activations in SPM using a macroscopic anatomical parcellation of the MNI MRI single-subject brain. NeuroImage, 15(1), 273-289.

Vohs, K. D., Mead, N. L., \& Goode, M. R. (2006). The psychological consequences of money. Science, 314(5802), 1154-1156.

Wall, P. D. (1999). Pain: The science of suffering. London: Weidenfeld \& Nicolson.

Watson-Jones, R. E., Whitehouse, H., \& Legare, C. H. (2016). In-group ostracism increases high-fidelity imitation in early childhood. Psychological Science.

Way, B. M., Taylor, S. E., \& Eisenberger, N. I. (2009). Variation in the $\mu-$ opioid receptor gene (OPRM1) is associated with dispositional and neural sensitivity to social rejection. Proceedings of the National Academy of Sciences, 106(35), 15079-15084.

Williams, K. D. (2009). Ostracism: A temporal need-threat model. In M. P. Zanna (Ed.), Advances in Experimental Social Psychology (Vol. 41, pp. 275-314). Academic Press.

Williams, K. D., Cheung, C. K. T., \& Choi, W. (2000). Cyberostracism: Effects of being ignored over the internet. Journal of Personality and Social Psychology, 79(5), 748-762.

Williams, K. D., \& Jarvis, B. (2006). Cyberball: A program for use in research on ostracism and interpersonal acceptance. Behavior Research Methods, Instruments, and Computers, 38, 174-180.

Williams, K. D., \& Sommer, K. L. (1997). Social ostracism by coworkers: Does rejection lead to loafing or compensation? Personality and Social Psychology Bulletin, 23(7), 693-706.

Wolf, L. D., \& Davis, M. C. (2014). Loneliness, daily pain, and perceptions of interpersonal events in adults with fibromyalgia. Health Psychology, 33(9), 929-937.

Woo, C.-W., Koban, L., Kross, E., Lindquist, M. A., Banich, M. T., Ruzic, L., ... Wager, T. D. (2014). Separate neural representations for physical pain and social rejection. Nature Communications, 5, 5380

Worsley, K. J. (2001). Statistical analysis of activation images. Functional MRI: An Introduction to Methods, 14, 251-270. 